University of Wollongong

Research Online

Australian Institute for Innovative Materials -

Papers

Australian Institute for Innovative Materials

$1-1-2014$

\title{
A computational study of carbon dioxide adsorption on solid boron
}

Qiao Sun

University of Queensland

Meng Wang

University of Queensland, mw088@uowmail.edu.au

Zhen Li

University of Wollongong, zhenl@uow.edu.au

Aijun Du

Queensland University of Technology

Debra J. Searles

University of Queensland

Follow this and additional works at: https://ro.uow.edu.au/aiimpapers

Part of the Engineering Commons, and the Physical Sciences and Mathematics Commons

Research Online is the open access institutional repository for the University of Wollongong. For further information contact the UOW Library: research-pubs@uow.edu.au 


\title{
A computational study of carbon dioxide adsorption on solid boron
}

\author{
Abstract \\ Capturing and sequestering carbon dioxide ( $\mathrm{CO} 2)$ can provide a route to partial mitigation of climate \\ change associated with anthropogenic $\mathrm{CO} 2$ emissions. Here we report a comprehensive theoretical study \\ of $\mathrm{CO} 2$ adsorption on two phases of boron, $\alpha-\mathrm{B} 12$ and $\gamma-\mathrm{B} 28$. The theoretical results demonstrate that the \\ electron deficient boron materials, such as $\alpha-B 12$ and $\gamma-B 28$, can bond strongly with CO2 due to Lewis \\ acid-base interactions because the electron density is higher on their surfaces. In order to evaluate the \\ capacity of these boron materials for $\mathrm{CO} 2$ capture, we also performed calculations with various degrees \\ of $\mathrm{CO} 2$ coverage. The computational results indicate $\mathrm{CO} 2$ capture on the boron phases is a kinetically and \\ thermodynamically feasible process, and therefore from this perspective these boron materials are \\ predicted to be good candidates for $\mathrm{CO} 2$ capture. \\ Keywords \\ dioxide, adsorption, solid, boron, study, computational, carbon \\ Disciplines \\ Engineering | Physical Sciences and Mathematics \\ Publication Details \\ Sun, Q., Wang, M., Li, Z., Du, A. \& Searles, D. J. (2014). A computational study of carbon dioxide adsorption \\ on solid boron. Physical Chemistry Chemical Physics, 16 (25), 12695-12702.
}




\title{
A Computational Study of Carbon Dioxide Adsorption on Solid Boron
}

\author{
Qiao Sun ${ }^{*}, \mathrm{a}$, Meng Wang ${ }^{\mathrm{a}, \mathrm{b}}$, Zhen $\mathrm{Li}^{*}{ }^{*}$, , Aijun $\mathrm{Du}^{\mathrm{d}}$ and Debra J. Searles ${ }^{*}, \mathrm{a}, \mathrm{e}$
}

\begin{abstract}
Capturing and sequestering carbon dioxide $\left(\mathrm{CO}_{2}\right)$ can provide a route to partial mitigation of climate change associated with anthropogenic $\mathrm{CO}_{2}$ emissions. Here we report a comprehensive theoretical study of $\mathrm{CO}_{2}$ adsorption on two phases of boron, $\alpha-\mathrm{B}_{12}$ and $\gamma-\mathrm{B}_{28}$. The theoretical results demonstrate that the electron deficient boron materials, such as $\alpha-B_{12}$ and $\gamma-B_{28}$, can bond strongly with $\mathrm{CO}_{2}$ due to Lewis acid-base interactions because the electron density is higher on their surfaces. In order to evaluate the capacity of these boron materials for $\mathrm{CO}_{2}$ capture, we also performed calculations with various degrees of $\mathrm{CO}_{2}$ coverage. The computational results indicate $\mathrm{CO}_{2}$ capture on the boron phases is a kinetically and thermodynamically feasible process, and therefore from this perspective these boron materials are predicted to be good candidates for $\mathrm{CO}_{2}$ capture.
\end{abstract}

\section{Introduction}

Carbon dioxide, $\mathrm{CO}_{2}$, is a greenhouse gas whose concentration in the atmosphere has been increasing since the industrial revolution, and this increase is largely caused by the burning of fossil fuels. Therefore it is essential that this trend be halted, and new technologies aimed at removing $\mathrm{CO}_{2}$ from combustion products to reduce its concentration in the atmosphere are being developed. ${ }^{1,2}$ An alternative approach to reduction of $\mathrm{CO}_{2}$ from combustion is to select fuels that produce less $\mathrm{CO}_{2}$ on combustion than conventional fossil fuels (e.g. natural gas), or no $\mathrm{CO}_{2}\left(\mathrm{H}_{2}\right)$. These fuels often contain contaminants including $\mathrm{CO}_{2}$, so $\mathrm{CO}_{2}$ capture from these resources before combustion is necessary and is a well-established process in industry. The most common processes involve treatment with amine solutions or chilled ammonia, however these processes have some problems in that they are not energy efficient, the amine is toxic and solvent can easily be lost. ${ }^{2,3}$ In both these approaches to reducing $\mathrm{CO}_{2}$ in the atmosphere, it is important that new environmentally friendly and economically feasible processes for $\mathrm{CO}_{2}$ capture be developed.

${ }^{a}$ Centre for Theoretical and Computational Molecular Science, Australian Institute for Bioengineering and Nanotechnology, The University of Queensland, QLD 4072, Brisbane, Australia. Email: q.sun@uq.edu.au; d.bernhardt@uq.edu.au

${ }^{b}$ Center for Bioengineering and Biotechnology, China University of Petroleum (East China), Qingdao 266555, China.

${ }^{c}$ Institute of Superconducting \& Electronic Materials, The University of Wollongong, NSW 2500, Australia.Email: zhenl@uow.edu.au

${ }^{d}$ School of Chemistry, Physics and Mechanical Engineering, Queensland University of Technology, Brisbane, QLD 4001, Australia.

${ }^{e}$ School of Chemistry and Molecular Biosciences, The University of Queensland, QLD 4072, Brisbane, Australia.

Solid adsorbents are anticipated to play a key role in new technologies, and there have been many materials considered in recent years. ${ }^{4}$ To be of practical use the materials must be able to strongly adsorb $\mathrm{CO}_{2}$ and have large surface areas, however many materials only weakly bind $\mathrm{CO}_{2}$. In this work we find that solid boron materials such as $\alpha-\mathrm{B}_{12}$ and $\gamma-\mathrm{B}_{28}$ can adsorb $\mathrm{CO}_{2}$ strongly and therefore may be useful materials for $\mathrm{CO}_{2}$ capture.
Boron readily bonds with other boron atoms, forming a variety of different structures with complex features such as three-center twoelectron bonds or electron deficient bonds. In the pure boron solids, the $\mathrm{B}_{12}$ icosahedron is the basic structural unit which can be flexibly linked or fused to form rigid structures, ${ }^{5-10}$ and the existence of this unit and it connectivity is associated with the electron deficiency, or hypovalency, of boron. Four reported boron phases correspond to the pure element: rhombohedral $\alpha-\mathrm{B}_{12}{ }^{6,9,11,12}$ and $\beta-\mathrm{B}_{106}{ }^{5}$ (with 12 and 106 atoms in the unit cell, respectively), tetragonal $\mathrm{T}-192^{7}$ (with 190-192 atoms per unit cell) and $\gamma-B_{28}^{8,13,14}$ (with 28 atoms in the unit cell), whereas there is a large variety of boron-rich compounds. Much work on boron rich compounds has been carried out due to their physical and chemical properties which have resulted in research for their suitability in applications from nuclear reactors to super-hard, thermoelectric and high-energy materials as well as hydrogen storage materials. ${ }^{8,12,15-18}$ In this study, we will investigate $\mathrm{CO}_{2}$ capture using $\alpha-\mathrm{B}_{12}$ and $\gamma-\mathrm{B}_{28}$. The $\alpha-\mathrm{B}_{12}$ phase consists of one $B_{12}$ icosahedron per unit cell and $\gamma-B_{28}$ consists of icosahedral $B_{12}$ clusters and $\mathrm{B}_{2}$ pairs in a NaCl-type arrangement. ${ }^{8}$ It has been shown that the electronic properties of the $B_{2}$ pairs and $B_{12}$ clusters in $\gamma-B_{28}$, are different, and this results in charge transfer between them. ${ }^{8}$ For $\alpha-B_{12}$ and $\gamma-B_{28}$, our study found that there is charge transfer among the atoms on their surfaces and the internal atoms, indicating that the $\alpha-B_{12}$ and $\gamma-B_{28}$ slabs are amphoteric with acidic and basic sites. The regioselectivity of $\alpha-\mathrm{B}_{12}$ and $\gamma-\mathrm{B}_{28}$ indicate $\mathrm{CO}_{2}$ (Lewis acid) might form strong interactions with the basic sites of their $\mathrm{B}$ materials due to Lewis acid-base interactions. In order to test this hypothesis, we have carried out DFT calculations of $\mathrm{CO}_{2}$ capture on $\alpha-\mathrm{B}_{12}$ and $\gamma-\mathrm{B}_{28}$ surfaces. The primary motivation of the theoretical study is to stimulate further experiments to verify our prediction that $\mathrm{CO}_{2}$ can be captured by these boron materials.

\section{Computational methods}

Ab initio DFT calculations are performed with the DMol3 module in Material Studio. ${ }^{19,20}$ The configurations of $\mathrm{CO}_{2}$ adsorbed on the boron phases are fully optimized using the generalized gradient approximation $^{21}$ treated by the Perdew-Burke-Ernzerhof exchangecorrelation potential with long rang dispersion correction carried out using the Grimme's scheme ${ }^{22}$. This method has been used to successfully determine the geometrical, energetic and electronic structural properties of boron clusters, boron phases and boron 
containing materials. ${ }^{23-29}$ The basis set employed is an all-electron double-numerical atomic orbital basis set, augmented by $\mathrm{d}$ polarization functions (DNP). The cell parameters of $\alpha-B_{12}$ and $\gamma-B_{28}$ in the calculations are all optimized and are consistent with the experimental values. ${ }^{8,11}$ Detailed information on the cell parameters is listed in our previous publication. ${ }^{27}$ The slab thicknesses of $\alpha-B_{12}$ and $\gamma-B_{28}$ are $8.012 \AA$ and $6.914 \AA$ (corresponding to two layers of $\mathrm{B}_{12}$ or $\mathrm{B}_{14}$ clusters), respectively. The $2 \times 2 \alpha$-boron (001) and $\gamma$ boron (001) surfaces were chosen with a $15 \AA$ vacuum above the slab in order to avoid interactions between their periodic images, and the Brillouin zone is sampled by $6 \times 6 \times 1$ k-points using the Monkhorst-Pack scheme.

The calculations of $\mathrm{CO}_{2}$ adsorption on $\alpha-\mathrm{B}_{12}(001)$ and $\gamma-\mathrm{B}_{28}(001)$ surfaces are based on the fully optimized boron surfaces. ${ }^{27}$ The adsorption energy of $\mathrm{CO}_{2}$ on $\alpha-\mathrm{B}_{12}$ and $\gamma-\mathrm{B}_{28}$ are calculated from Eq. 1:

$E_{a d s}=E_{\left(\text {boron phase- } \mathrm{CO}_{2}\right)}-E_{\mathrm{CO}_{2}}-E_{(\text {boron phase })}$

where $E_{\left(\text {boron phase- } \mathrm{CO}_{2}\right)}$ is the total energy of the boron surface with a $\mathrm{CO}_{2}$ molecule adsorbed. In order to better clarify the adsorption and the nature of the interaction of $\mathrm{CO}_{2}$ with $\alpha-\mathrm{B}_{12}$ and $\gamma-\mathrm{B}_{28}$, atoms in molecules (AIM) theory has been employed in the study. Based on the optimized structures at the DFT-D level, we calculate the wavefunctions at the B3LYP/6-31G(d) level of theory, ${ }^{21}$ we then use AIM theory, which has been used to successfully determine intermolecular interactions of different systems. ${ }^{27,30,31}$ In the AIM analyses, ${ }^{32}$ the existence of an interaction is indicated by the presence of a bond critical point (BCP), and the strength of the bond can be estimated from the magnitude of the electron density $\left(\rho_{\mathrm{bcp}}\right)$ at the BCP. Similarly, the ring or cage structures are characterized by the existence of a ring critical point (RCP) or cage critical point (CCP). Furthermore, the nature of the molecular interaction can be predicted from the topological parameters at the BCP, such as the the acian of electron density $\left(\nabla^{2} \rho_{\mathrm{bcp}}\right)$ and energy density $\left(H_{\mathrm{bcp}}\right)$. The topological analysis of the system was carried out via the AIMALL program. $^{32}$

The transition states between chemisorbed and physisorbed $\mathrm{CO}_{2}$ have been investigated using the complete LST (linear synchronous transit)/QST (quadratic synchronous transit) method ${ }^{33}$ implemented in the DMol3 code. The reactants and products correspond to the optimized structures of $\mathrm{CO}_{2}$ physisorbed and chemisorbed on $\alpha-\mathrm{B}_{12}$ and $\gamma-B_{28}$ surfaces, respectively. Electron distributions and transfer mechanisms are determined with the Mulliken method. ${ }^{34}$

\section{Results and discussion}

The $\alpha-B_{12}$ and $\gamma-B_{28}$ slabs were optimized and the fully relaxed $\alpha-B_{12}$ (001) and $\gamma-B_{28}(001)$ surfaces with cell vectors are shown in Fig. 1(a) and (b), respectively. We firstly investigated the Mulliken atomic charge distributions on the $\alpha-B_{12}(001)$ and $\gamma-B_{28}(001)$ surfaces and then carried out a study of the mechanism of $\mathrm{CO}_{2}$ adsorption on the surfaces of the two boron materials. All the possible sites for $\mathrm{CO}_{2}$ adsorption on $\alpha-\mathrm{B}_{12}$ and $\gamma-\mathrm{B}_{28}$ surfaces have been considered. In this manuscript we will discuss the strongest adsorption sites which we classify as having two different types of interaction: type $\mathrm{A}$ and $\mathrm{B}$. In type $\mathrm{A}$ interactions, the carbon atom and one oxygen atom in the $\mathrm{CO}_{2}$ molecule directly connect with two boron atoms, and in type $\mathrm{B}$ interactions, two oxygen atoms of the $\mathrm{CO}_{2}$ molecule directly connect with the boron atoms of the $\alpha-\mathrm{B}_{12}$ and $\gamma-\mathrm{B}_{28}$ surfaces.

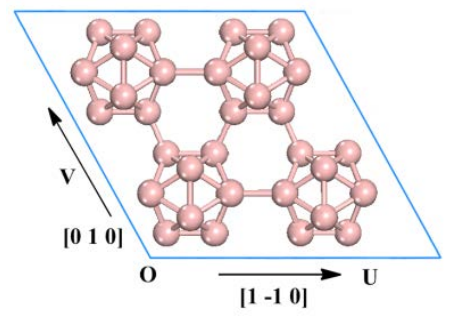

(a)

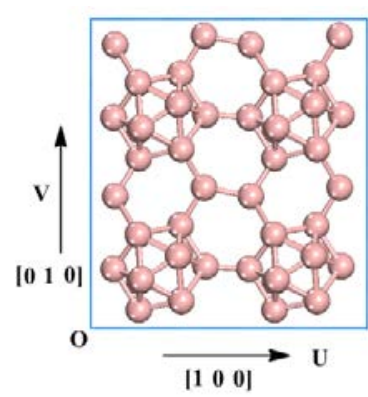

(b)
Fig. 1 The top view of the surfaces of fully relaxed $\alpha-B_{12}(001)$ and $\gamma-B_{28}(001)$ slabs with cell vectors shown. Atom color code: pink, boron.

\subsection{Atomic charge distributions of $\alpha-B_{12}$ and $\gamma-B_{28}$}

It is well known that boron phases, such as $\alpha-B_{12}$ and $\gamma-B_{28}$, are electron deficient materials because there is only one electron on the p orbital of each boron atom, while $\mathrm{CO}_{2}$ is a Lewis acid and it would prefer to gain electrons in reactions. Because of this the electron deficient boron materials might not be expected to be good adsorbents for $\mathrm{CO}_{2}$ capture. However, from the Mulliken atomic charge distributions of the $\alpha-\mathrm{B}_{12}$ and $\gamma-\mathrm{B}_{28}$ slabs that we modeled we can see that there is electron transfer from the atoms within the slabs to the surface atoms of $\alpha-B_{12}$ and $\gamma-B_{28}$. Fig. 2 shows the optimized $\alpha-B_{12}$ and $\gamma-B_{28}$ structures and the Mulliken atomic charges for the atoms labeled in Fig. 2 are listed in Table 1.

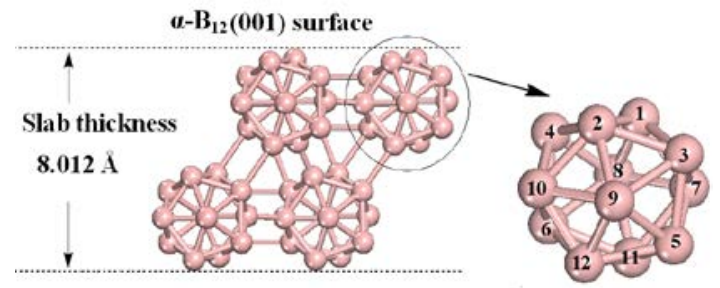

(a)

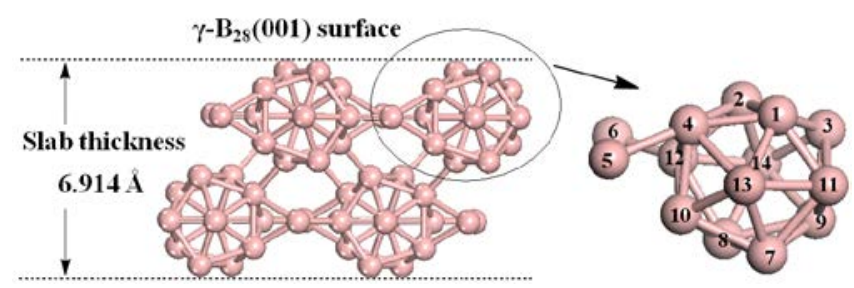

(b)

Fig. 2 The side view of the optimized $\alpha-B_{12}(001)$ and $\gamma-B_{28}(001)$ slabs. Mulliken atomic charges of these atoms (with atom numbers in Fig. 2) are listed in Table 1.

The charges on the surface atoms of $\alpha-\mathrm{B}_{12}$ are $-0.366 \mathrm{e}$ (atom B1), 0.321 e (atom B2), -0.008e (atom B3 and B4) according to the Mulliken atomic charge analysis, and the atoms in the internal part of the slab have positive charges. The Mulliken atomic charge distributions of $\gamma-B_{28}$ are similar to those of the $\alpha-B_{12}$ slab: the surface atoms B1 and B2 have negative charges of $-0.311 \mathrm{e}, \mathrm{B} 3$ and B4 have negative charges of -0.098e, and the internal atoms either have positive charges (atoms B9-B14) or are slightly negative 
(atoms B7 and B8). The charge difference between the atoms on the surfaces and the internal atoms mean that the $\alpha-\mathrm{B}_{12}$ and $\gamma-\mathrm{B}_{28}$ slabs are regioselective and amphoteric, with both acidic and basic sites. Similar behaviour in boron materials, such as $B_{80}$, has been investigated preciously by Muya et al., who found the cap atoms of $\mathrm{B}_{80}$ act as acid sites and the frame atoms act as basic sites in this regioselective molecule. ${ }^{35}$ From the above analysis we have shown that, in principle, $\mathrm{CO}_{2}$ (Lewis acid) will form strong interactions with the basic sites of $\alpha-B_{12}$ and $\gamma-B_{28}$ due to Lewis acid-base interactions. In the following section, we will investigate $\mathrm{CO}_{2}$ the mechanism of $\mathrm{CO}_{2}$ adsorption on the $\alpha-\mathrm{B}_{12}$ and $\gamma-\mathrm{B}_{28}$ surfaces.

Table 1 Atom number and Mulliken atomic charges (e) of the optimized $\alpha-\mathrm{B}_{12}$ and $\gamma-\mathrm{B}_{28}$ slabs.

\begin{tabular}{cccc}
\hline \multicolumn{2}{c}{$\alpha-\mathrm{B}_{12}$} & \multicolumn{2}{c}{$\gamma-\mathrm{B}_{28}$} \\
\hline Atom number & Atomic charge & Atom number & Atomic charge \\
\hline B1 & -0.366 & B1 & -0.311 \\
B2 & -0.321 & B2 & -0.311 \\
B3 & -0.008 & B3 & -0.098 \\
B4 & -0.008 & B4 & -0.098 \\
B5 & 0.139 & B5 & -0.074 \\
B6 & 0.139 & B6 & -0.074 \\
B7 & 0.119 & B7 & -0.025 \\
B8 & 0.119 & B8 & -0.025 \\
B9 & 0.033 & B9 & 0.133 \\
B10 & 0.033 & B10 & 0.133 \\
B11 & 0.066 & B11 & 0.171 \\
B12 & 0.055 & B12 & 0.171 \\
& & B13 & 0.204 \\
& & B14 & 0.204 \\
\hline
\end{tabular}

\section{$3.2 \mathrm{CO}_{2}$ adsorption on the $\alpha-\mathrm{B}_{12}$ surface}

Currently 16 allotropes of elemental boron have been reported, with the $\alpha$-boron structure being the simplest. ${ }^{18}$ It contains 12 atoms in a rhombohedral unit cell, forming a slightly distorted icosahedral $\mathrm{B}_{12}$. In this section, we will investigate the reaction mechanism of $\mathrm{CO}_{2}$ adsorption on $\alpha-B_{12}$. We have identified two ways in which $\mathrm{CO}_{2}$ adsorbs on $\alpha-\mathrm{B}_{12}$, labelled type $\mathrm{A}$ and type $\mathrm{B}$. In type $\mathrm{A}$ one $\mathrm{O}$ atom and the $\mathrm{C}$ atom of $\mathrm{CO}_{2}$ bond with one $\mathrm{B}-\mathrm{B}$ bond of $\alpha-\mathrm{B}_{12}$; and in type $\mathrm{B}$ two $\mathrm{O}$ atoms of $\mathrm{CO}_{2}$ interact with one $\mathrm{B}-\mathrm{B}$ bond of $\alpha-\mathrm{B}_{12}$. Fig. 3 (a) shows the optimized structures of the two possible minimum-energy type A configurations, and the transition states for the process of $\mathrm{CO}_{2}$ adsorption on the $\alpha-\mathrm{B}_{12}$ surface. Corresponding results for type $\mathrm{B}$ interactions have been listed in the supporting information, see Fig. S1 (a). The important structural properties, relative energies and the electron transfers from the $\alpha-\mathrm{B}_{12}$ to $\mathrm{CO}_{2}$ are listed in Table 2 and Table S1 in supporting information. For the two types of interaction of $\mathrm{CO}_{2}$ with $\alpha-\mathrm{B}_{12}$, we can see that the chemisorbed type A configuration is the most stable, so the discussion will focus on the adsorption through interactions of type A. For $\mathrm{CO}_{2}$ capture on $\alpha-\mathrm{B}_{12}$ through type $\mathrm{A}$ interactions, we identified two stationary states, corresponding to physisorption and chemisorption. In the physisorbed configuration, $\mathrm{CO}_{2}$ interacts with one $\mathrm{B}-\mathrm{B}$ bond of $\alpha-\mathrm{B}_{12}$ and lies parallel to it. The $\mathrm{O}-\mathrm{C}-\mathrm{O}$ angle is $179.9^{\circ}$ and $\mathrm{B}-\mathrm{O}$ distance is approximately $3.1 \AA$, the long distance indicates the interaction is very weak and the adsorption is mainly due to the van der Waals interaction of $\mathrm{CO}_{2}$ and $\alpha-\mathrm{B}_{12}$.

Table 2 Adsorption energy in $\mathrm{kcal} / \mathrm{mol}$, bond distance (r) in $\AA$, bond angle $(\alpha)$ in deg and charge transfer (CT) in electrons for the type A of $\mathrm{CO}_{2}$ adsorption on $\alpha-\mathrm{B}_{12}$ and $\gamma-\mathrm{B}_{28}$ surfaces.

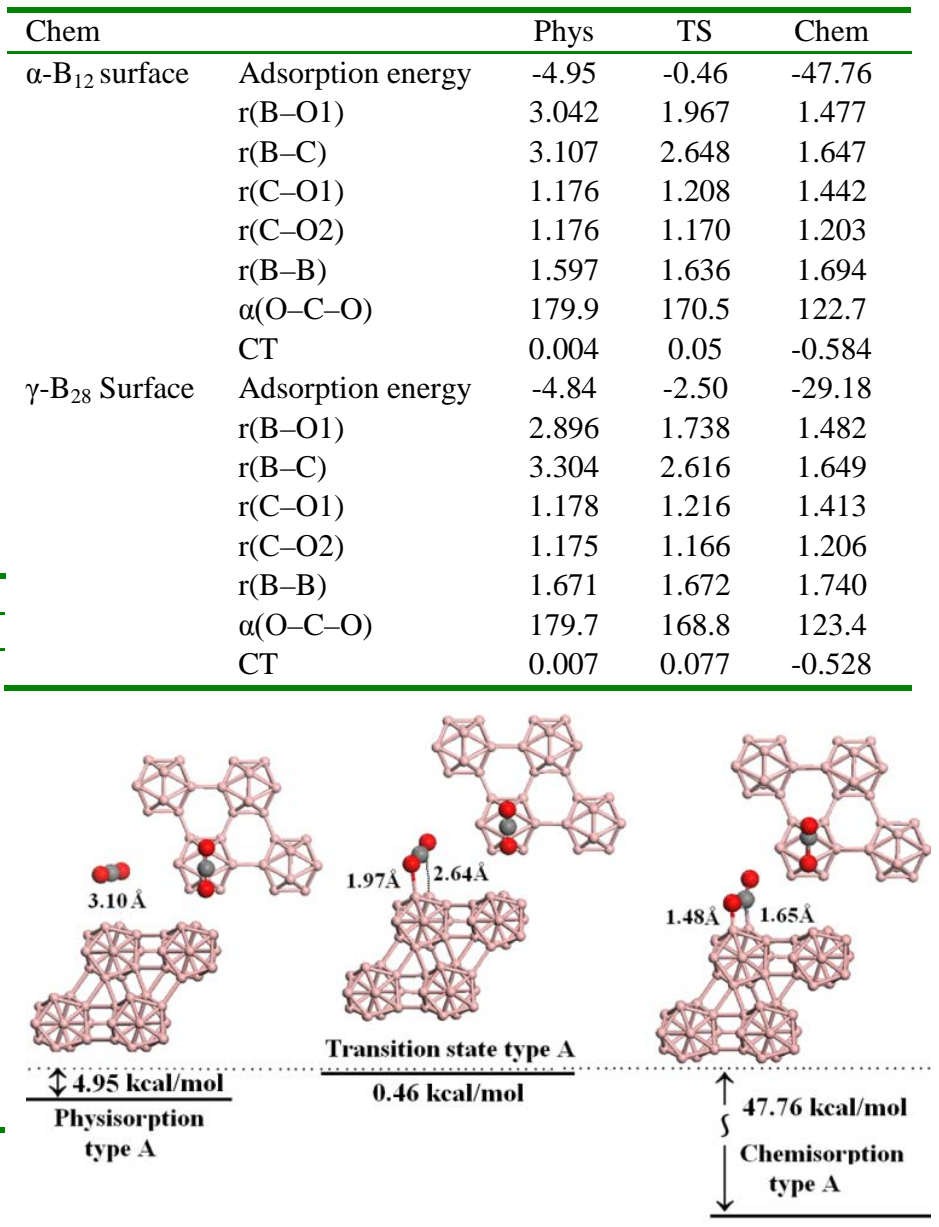

(a)

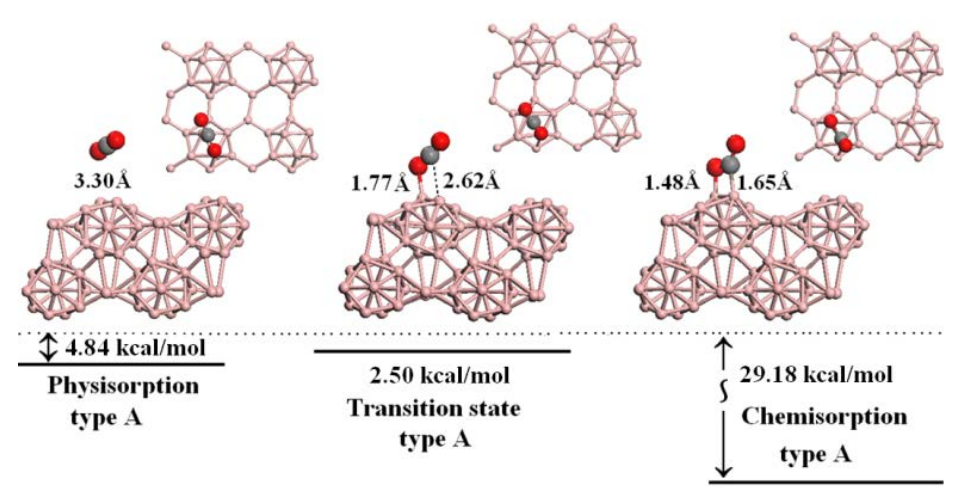

(b)

Fig. 3 Computed minimum energy configurations and transition state for $\mathrm{CO}_{2}$ adsorption on the $\alpha-\mathrm{B}_{12}$ (a) and $\gamma-\mathrm{B}_{28}$ (b) surfaces involving type $\mathrm{A}$ interactions (top and side view of the two minimum energy configurations and transition state).

Table 3 Atom number and Mulliken atomic charges (e) and the sum of charge (e) of $\mathrm{CO}_{2}$, the boron cell of $\alpha-\mathrm{B}_{12} \mathrm{CO}_{2}$ and $\gamma-\mathrm{B}_{28}-\mathrm{CO}_{2}$ complexes (chemisorbed configurations) as well as the charge transfer of $\alpha-\mathrm{B}_{12} \mathrm{CO}_{2}$ (CT1) and $\gamma-\mathrm{B}_{28}-\mathrm{CO}_{2}$ (CT2) complexes comparing with those of the isolated forms.

\begin{tabular}{llllll}
\hline Atom type/Sum & $\mathrm{CO}_{2}$ & $\alpha-\mathrm{B}_{12}$ & $\mathrm{CT} 1$ & $\gamma-\mathrm{B}_{28}$ & $\mathrm{CT} 2$ \\
\hline
\end{tabular}




\begin{tabular}{cccrrr}
\hline of charge & \multicolumn{3}{c}{$\mathrm{CO}_{2}$} & & $-\mathrm{CO}_{2}$ \\
\hline O1 & -0.284 & -0.481 & -0.197 & -0.460 & -0.263 \\
C & 0.568 & 0.246 & -0.322 & 0.278 & 0.600 \\
O2 & -0.284 & -0.349 & -0.065 & -0.346 & -0.281 \\
Sum of charge & 0.0 & -0.584 & & -0.528 & \\
B1 & & -0.186 & 0.180 & -0.192 & 0.119 \\
B2 & & 0.110 & 0.431 & 0.065 & 0.376 \\
B3 & & 0.001 & 0.009 & -0.011 & 0.087 \\
B4 & & 0.000 & 0.008 & -0.007 & 0.091 \\
B5 & & 0.036 & -0.103 & -0.098 & -0.024 \\
B6 & 0.036 & -0.103 & -0.057 & 0.017 \\
B7 & 0.071 & -0.048 & -0.010 & 0.015 \\
B8 & & 0.071 & -0.048 & -0.018 & 0.007 \\
B9 & & 0.082 & 0.049 & 0.125 & -0.008 \\
B10 & 0.081 & 0.048 & 0.126 & -0.007 \\
B11 & 0.069 & 0.003 & 0.095 & -0.076 \\
B12 & 0.057 & 0.002 & 0.116 & -0.055 \\
B13 & & & & 0.093 & -0.111 \\
B14 & & & & 0.077 & -0.127 \\
Sum of charge & & 0.428 & & 0.304 & \\
\hline
\end{tabular}

The adsorption energy of the physisorbed $\mathrm{CO}_{2}$ is calculated to be $4.95 \mathrm{kcal} / \mathrm{mol}$. The weak interaction is also confirmed by the negligible charge transfer between the $\alpha-\mathrm{B}_{12}$ and $\mathrm{CO}_{2}$ molecule (with a value of only -0.004e). Molecular graphs for $\mathrm{CO}_{2}$ adsorption on $\alpha$ $\mathrm{B}_{12}$ are displayed in Fig. 4. We can see from Fig. 4 (a) that the interaction between $\mathrm{CO}_{2}$ and $\alpha-\mathrm{B}_{12}$ can be confirmed by the existence of the bond critical point (BCP) of the $\mathrm{O}-\mathrm{B}$ contact. The calculated topological parameters at the BCPs of the $\alpha-B_{12}$ are listed in Table S2 in supporting information. For the physisorbed configurations, the electron densities at the BCPs of the bonds between $\mathrm{CO}_{2}$ and $\alpha-\mathrm{B}_{12}$ are small (Table S2), which is consistent with a weak interaction. When $\mathrm{CO}_{2}$ is chemisorbed on $\alpha-\mathrm{B}_{12}$, the $\mathrm{B}-$ $\mathrm{C}$ and $\mathrm{B}-\mathrm{O}$ bond lengths shorten and a four-membered ring is formed. The $\mathrm{O}-\mathrm{C}-\mathrm{O}$ bond angle is $122.7^{\circ}$, and one $\mathrm{C}=\mathrm{O}$ doublebond breaks and stretches from $1.176 \AA$ to $1.442 \AA$ due to the bonding interaction that is formed between the $\mathrm{B}-\mathrm{B}$ bond of $\alpha-\mathrm{B}_{12}$ and $\mathrm{C}-\mathrm{O}$ bond of $\mathrm{CO}_{2}$. Table 3 lists the Mulliken atomic charges (e) of the $\alpha-\mathrm{B}_{12}-\mathrm{CO}_{2}$ and $\gamma-\mathrm{B}_{28}-\mathrm{CO}_{2}$ complexes (chemisorbed configurations) and the charge transfers of $\mathrm{CO}_{2}$ and the boron cells which directly connect with $\mathrm{CO}_{2}$ of $\alpha-\mathrm{B}_{12}-\mathrm{CO}_{2}$ (CT1) and $\gamma-\mathrm{B}_{28}-$ $\mathrm{CO}_{2}$ (CT2) complexes comparing with those of the isolated forms. A Mulliken charge population analysis shows that there is -0.584 electron charge transfer from $\alpha-\mathrm{B}_{12}$ to the $\mathrm{CO}_{2}$ molecule, and the charge redistributions of the boron atoms at the $\mathrm{CO}_{2} / \mathrm{B}$ interface is the main contribution for the charge transfer. The $\mathrm{CO}_{2}$ molecule undergoes structural distortion to a bent geometry and forms a $\mathrm{C}-\mathrm{O}-$ $\mathrm{B}-\mathrm{B}$ four-membered ring, in which the $\mathrm{B}-\mathrm{C}$ and $\mathrm{B}-\mathrm{O}$ distances are $1.647 \AA$ and $1.477 \AA$, respectively. The short distance indicates a strong interaction between the $\mathrm{CO}_{2}$ molecule and $\alpha-\mathrm{B}_{12}$, with the calculated adsorption binding energy is $47.76 \mathrm{kcal} / \mathrm{mol}$.

Here we note that the interaction between $\mathrm{CO}_{2}$ and $\alpha-\mathrm{B}_{12}$ is the strongest value for $\mathrm{CO}_{2}$ adsorption on substrates so far, as far as we are aware. Moreover, the calculated barrier between the physisorbed and chemisorbed configurations is $4.49 \mathrm{kcal} / \mathrm{mol}$. As shown in Table S2, as we move from the physisorbed configuration (Fig. 4(a)), to the transition state (Fig. 4(b)), to the chemisorbed configuration (Fig. 4(c)) the electron densities at the BCPs for the O1-B bonds increase, which is consistent with the adsorption process resulting in strengthening of the interaction. In addition, the O1-B bond distances decrease from $3.042 \AA$ for the physisorbed structure, 1.967 $\AA$ for the transition state structure and $1.477 \AA$ when the $\mathrm{CO}_{2}$ is chemisorbed, and the $\mathrm{C}-\mathrm{B}$ bond distances decrease with the values of $3.107 \AA, 2.648 \AA$ and $1.647 \AA$ for the three structures, respectively. The strong interaction between $\mathrm{CO}_{2}$ and $\alpha-\mathrm{B}_{12}$, and low

barrier from the physisorbed to chemisorbed configurations demonstrate that the $\mathrm{CO}_{2}$ adsorption on $\alpha-\mathrm{B}_{12}$ is a kinetically favorable process. In addition, we have listed variation of thermodynamic properties with temperatures $(\mathrm{K})$ for adsorption of free $\mathrm{CO}_{2}$ on the $\alpha-\mathrm{B}_{12}$ (a) and $\gamma-\mathrm{B}_{28}$ (b) surfaces to form chemisorbed configurations (type A) in Figure 5. Fig. 5 (a) shows the temperature dependence of thermodynamic properties $\Delta \mathrm{G}$ (kcal/mol), $\Delta H$ $(\mathrm{kcal} / \mathrm{mol})$ and $\Delta \mathrm{S}(\mathrm{cal} / \mathrm{mol} \mathrm{K})$ for gaseous $\mathrm{CO}_{2}$ capture on $\alpha-\mathrm{B}_{12}$ to form a chemisorbed configuration of type A. It clearly shows that the $\Delta \mathrm{S}$ of the reaction increases as temperature increases from 200 to $1000 \mathrm{~K}$ and $\Delta \mathrm{H}$ is almost constant over the whole temperature range. The resulting negative $\Delta \mathrm{G}$ indicates the adsorption reaction process is spontaneous for the temperatures considered.

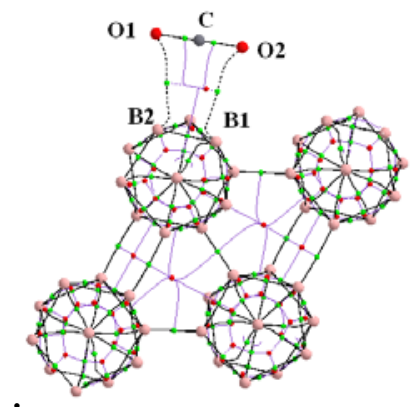

(a) $\alpha-B_{12}-$ phy

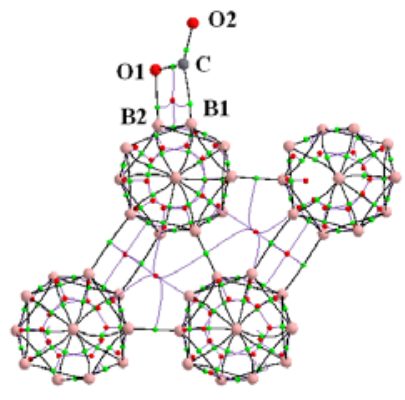

(c) $\alpha-B_{12}-$ chem

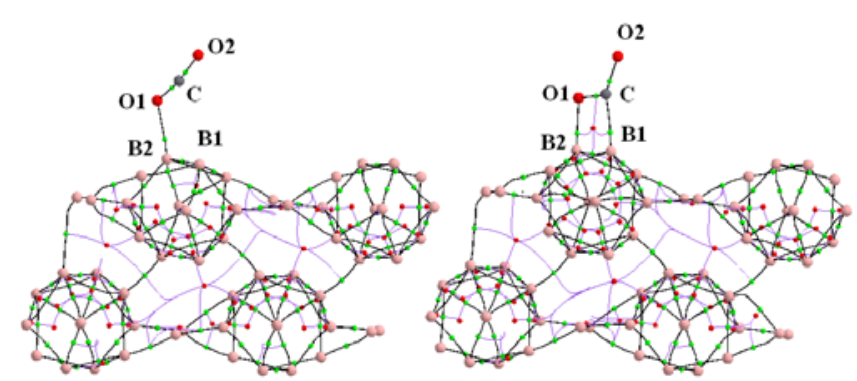

(e) $\gamma-\mathrm{B}_{28}-\mathrm{TS}$

(f) $\gamma-B_{28}-$ chem

Fig. 4 The molecular graphs of the minimum energy structures and transition states of $\mathrm{CO}_{2}$ adsorbed on the $\alpha-\mathrm{B}_{12}$ and $\gamma-\mathrm{B}_{28}$ surfaces with type $\mathrm{A}$ interactions, where the bond critical points (BCPs), ring critical points (RCPs) and cage critical point (CCP) are denoted as small green, red and blue dots, respectively.

For type $\mathrm{B}$ interactions of $\mathrm{CO}_{2}$ with $\alpha-\mathrm{B}_{12}$, we also identified two local minima and the transition state between those physisorbed and chemisorbed states. The physisorbed configuration (Fig. S1(a)) of $\mathrm{CO}_{2}$ on $\alpha-\mathrm{B}_{12}$ is very similar to that observed in the type $\mathrm{A}$ physisorbed configuration. The chemisorbed configuration (Fig. $\mathrm{S} 1(\mathrm{a})$ ) has a $\mathrm{O}-\mathrm{C}-\mathrm{O}-\mathrm{B}-\mathrm{B}$ five-membered ring. In this configuration, the two $\mathrm{C}-\mathrm{O}$ bonds have stretched from $1.176 \AA$ to $1.330 \AA$ and the 
$\mathrm{O}-\mathrm{C}-\mathrm{O}$ bond angle is $115.4^{\circ}$. The $\mathrm{B}-\mathrm{B}$ site is also pulled out of the material and elongated by $0.10 \AA$. The two B-O distances are 1.494 $\AA$ which is slight longer than the $\mathrm{O}-\mathrm{B}$ distance in the type $\mathrm{A}$ configuration for $\alpha-B_{12}(1.447 \AA)$. The adsorption energy of this chemisorbed configuration is $41.81 \mathrm{kcal} / \mathrm{mol}$, which is slightly weaker than that for type $\mathrm{A}$. The calculated barrier between the physisorbed and chemisorbed configurations is $6.16 \mathrm{kcal} / \mathrm{mol}$. The strong interaction and low barrier between the physisorbed and chemisorbed configurations with type $\mathrm{B}$ interactions indicates $\mathrm{CO}_{2}$ capture is feasible through this mechanism. However, the $\mathrm{CO}_{2}$ capture process involving type A interactions will dominate because it has a stronger interaction energy and lower barrier to adsorption than type $\mathrm{B}$ interactions. Overall, the calculations demonstrate that the $\alpha-B_{12}$ phase can effectively capture $\mathrm{CO}_{2}$.

\section{$3.3 \mathrm{CO}_{2}$ adsorption on $\boldsymbol{\gamma}-\mathrm{B}_{28}$ surface}

The $\gamma-B_{28}$ phase with 28 atoms in the orthorhombic unit cell was originally discovered in $1965,{ }^{14}$ and is a hard semiconductor with a structure composed of $\mathrm{B}_{2}$ dumbbells and $\mathrm{B}_{12}$ icosahedra. There is debate about whether the two distinct structural units should be partially ionic or not. ${ }^{13,24,36}$ Our Mulliken charge analysis of the $\gamma$ $\mathrm{B}_{28}(001)$ slab indicate that the $\gamma-\mathrm{B}_{28}$ is amphoteric which contains both acidic and basic sites. This means that the electron deficient boron phase $\gamma-\mathrm{B}_{28}$ could denote electrons from its basic sites to $\mathrm{CO}_{2}$ to form a strong bond between $\mathrm{CO}_{2}$ and the basic sites of $\gamma-\mathrm{B}_{28}$, and therefore $\gamma-\mathrm{B}_{28}$ might be a good candidate for $\mathrm{CO}_{2}$ capture. In this section, we will discuss the absorption of $\mathrm{CO}_{2}$ on the $\gamma-\mathrm{B}_{28}$ surface. The computational results indicate that there are two types (A and $\mathrm{B}$ ) of adsorption of $\mathrm{CO}_{2}$ on $\gamma-\mathrm{B}_{28}$ surface, which are very similar to those seen in $\mathrm{CO}_{2}$ adsorption on $\alpha-\mathrm{B}_{12}$. Firstly, we will discuss $\mathrm{CO}_{2}$ adsorption on $\gamma-\mathrm{B}_{28}$ involving type $\mathrm{A}$ interactions. We identified two stationary states corresponding to physisorbed and chemisorbed $\mathrm{CO}_{2}$. The optimized structures of the two configurations as well as the transition state between them are shown in Fig. 3(b). The important structural properties, adsorption energies and the electron transfers from the boron phase to $\mathrm{CO}_{2}$ are listed in Table 2. From Fig. 3(b) we can see that the $\mathrm{CO}_{2}$ physisorbs by interaction with one $\mathrm{B}-\mathrm{B}$ bond of $\gamma-\mathrm{B}_{28}$, and is parallel to that bond. The $\mathrm{O}-\mathrm{C}-\mathrm{O}$ angle is $179.7^{\circ}$ and the $\mathrm{B}-\mathrm{O}$ distance is around $2.9 \AA$. The structure is very similar to that of the configuration of $\mathrm{CO}_{2}$ physisorbed on $\alpha-\mathrm{B}_{12}$ in a type A interaction (Fig. 3(a)). The adsorption energy of the physisorbed $\mathrm{CO}_{2}$ is calculated to be $4.84 \mathrm{kcal} / \mathrm{mol}$ so the interaction between $\mathrm{CO}_{2}$ and $\gamma-\mathrm{B}_{28}$ is very weak.

In its chemisorbed configuration, the $\mathrm{CO}_{2}$ molecule undergoes structural distortion to a bent geometry and forms a C-O-B-B fourmembered ring in which the $\mathrm{B}-\mathrm{C}$ and $\mathrm{B}-\mathrm{O}$ distances are $1.649 \AA$ and $1.482 \AA$, respectively. The $\mathrm{O}-\mathrm{C}-\mathrm{O}$ bond angle is $123.4^{\circ}$, and one $\mathrm{C}=\mathrm{O}$ double-bond breaks and stretches from $1.178 \AA$ to $1.413 \AA$ due to the bonding interaction that formed between the $\mathrm{B}-\mathrm{B}$ bond of the $\gamma-\mathrm{B}_{28}$ and the $\mathrm{C}-\mathrm{O}$ bond of $\mathrm{CO}_{2}$. The shorter distance indicates a stronger interaction between the $\mathrm{CO}_{2}$ molecule and $\gamma-\mathrm{B}_{28}$, and the calculated adsorption energy is $29.18 \mathrm{kcal} / \mathrm{mol}$. Compared with the type A energy of adsorption of $\mathrm{CO}_{2}$ on $\alpha-\mathrm{B}_{12}(47.76 \mathrm{kcal} / \mathrm{mol})$, the adsorption of $\mathrm{CO}_{2}$ on $\gamma-\mathrm{B}_{28}$ is much lower. The transition state between the physisorbed and chemisorbed configurations has been identified. Adsorption has also been verified by observation of an increase in the energy density at the BCP in going from the physisorbed state (Fig. 4(d)), to the transition state (Fig. 4(e)), and to chemisorbed state (Fig. 4(f)), which is consistent with strengthening of the interaction. In addition, the $\mathrm{O} 1-\mathrm{B}$ bond distances decrease from $2.896 \AA$ to $1.738 \AA$ and then $1.482 \AA$, and the $\mathrm{C}-\mathrm{B}$ bond distances decrease from $3.304 \AA$ to $2.616 \AA$ and then $1.649 \AA$ for the three structures, respectively. The calculated barrier between the physisorbed and chemisorbed configurations with type A interactions is $2.34 \mathrm{kcal} / \mathrm{mol}$. The variation of thermodynamic properties has also been calculated (Fig. 5(b)) in order to study the entropic and temperature effects of the chemisorption of gaseous $\mathrm{CO}_{2}$ on $\gamma-\mathrm{B}_{28}$. From Fig. $5(\mathrm{~b})$ we can see that $\Delta \mathrm{S}$ is monotonically increasing when the temperature is above $200 \mathrm{~K}$ and $\Delta \mathrm{H}$ has a slight linear increase over the whole temperature range considered. This results in $\Delta \mathrm{G}$ increasing almost linearly with an increase in temperature for $\mathrm{CO}_{2}$ capture on $\gamma-\mathrm{B}_{28}$, as the free $\mathrm{CO}_{2}$ is chemisorbed on the surface. Moreover, $\Delta \mathrm{G}$ is negative in the temperature range considered ( $200 \mathrm{~K}$ to $1000 \mathrm{~K}$ ), which indicates the adsorption of $\mathrm{CO}_{2}$ on $\gamma-\mathrm{B}_{28}$ to form the chemisorbed configuration is a spontaneous process for these temperatures. In summary, the low barrier and the negative $\Delta \mathrm{G}$ within the temperature range demonstrate that $\mathrm{CO}_{2}$ adsorption on $\gamma-\mathrm{B}_{28}$ is a kinetically and thermodynamically favorable process.

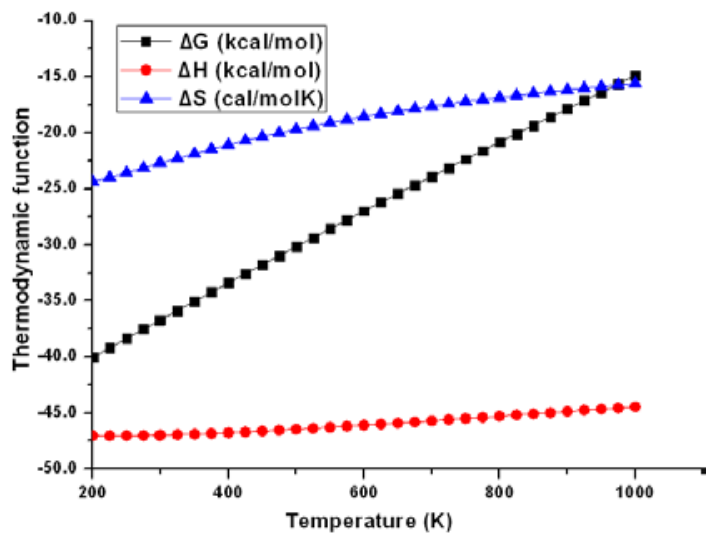

(a)

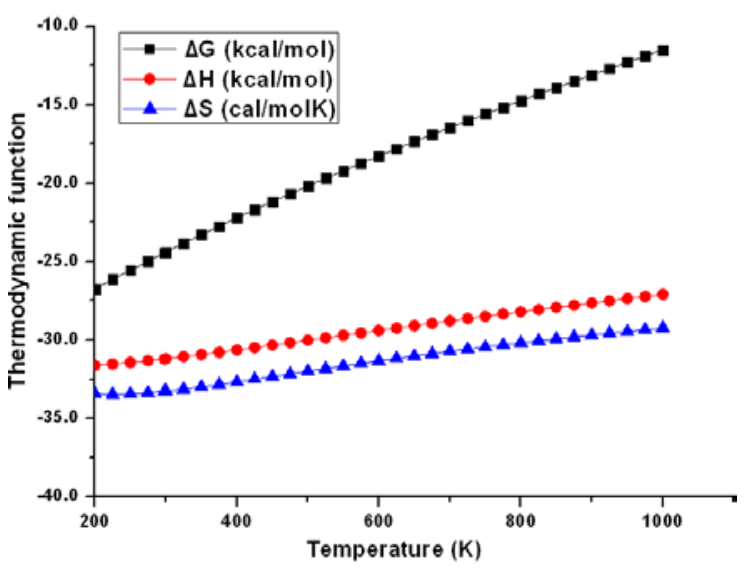

(b)

Fig. 5 Variation of thermodynamic properties with temperatures (K) for adsorption of free $\mathrm{CO}_{2}$ on the $\alpha-\mathrm{B}_{12}$ (a) and $\gamma-\mathrm{B}_{28}$ (b) surfaces to form chemisorbed configurations (type $\mathrm{A}$ ). Squares, triangles and circles correspond to the change in Gibbs free energy $(\mathrm{kcal} / \mathrm{mol})$, change in entropy (cal/mol K) and change in enthalpy ( $\mathrm{kcal} / \mathrm{mol})$, respectively.

For $\mathrm{CO}_{2}$ capture on $\gamma-\mathrm{B}_{28}$ with type $\mathrm{B}$ interactions, two local minima were also observed (chemisorbed and physisorbed configurations). In the physisorbed configuration, $\mathrm{CO}_{2}$ weakly interacts with $\gamma-\mathrm{B}_{28}$ with the adsorption energy of $4.89 \mathrm{kcal} / \mathrm{mol}$. The chemisorbed $\mathrm{CO}_{2}$ on $\gamma-\mathrm{B}_{28}$, has one five-membered ring $\mathrm{O}-\mathrm{C}-\mathrm{O}-\mathrm{B}-\mathrm{B}$, which is very similar to that of configuration of chemisorbed on $\mathrm{CO}_{2}$ on $\alpha-\mathrm{B}_{12}$ with type $\mathrm{B}$ interactions. In this configuration, the two $\mathrm{C}-\mathrm{O}$ bonds stretch from $1.176 \AA$ to $1.314 \AA$ and the $\mathrm{O}-\mathrm{C}-\mathrm{O}$ bond angle is $117.6^{\circ}$. The 
B-B site is also pulled out and elongated by $0.10 \AA$. The two B-O distances are $1.511 \AA$, which is slight longer than that of $\mathrm{O}-\mathrm{B}$ distance when type $A$ interactions result in $\mathrm{CO}_{2}$ bonding to $\gamma-\mathrm{B}_{28}$ $(1.482 \AA)$. The adsorption energy of this chemisorbed configuration is $21.78 \mathrm{kcal} / \mathrm{mol}$, which is slightly weaker than the absorption energy of the type A chemisorbed configuration. The barrier from the physisorbed to chemisorbed configurations with the type $B$ configuration is low with a value of $9.39 \mathrm{kcal} / \mathrm{mol}$. Moreover, the type A configuration will be the dominant one because it has a stronger adsorption energy and lower barrier than that due to type B interactions. In all, the computational results support the hypothesis that the $\gamma-\mathrm{B}_{28}$ phase can effectively capture $\mathrm{CO}_{2}$.

The different adsorption energies between $\mathrm{CO}_{2}$ and the two boron phases can be understood by analysis of their LUMO-HOMO energy gaps. According to molecular orbital theory, the frontier orbits and nearby molecular orbits are the most important factors determining the stability of molecules. The larger the difference between the frontier orbits, the more stable the molecular structure is. The energy gaps of $\Delta \mathrm{E}$ between their highest occupied molecular orbitals (HOMO) and their lowest unoccupied molecular orbitals (LUMO) $\left(\Delta \mathrm{E}=\mathrm{E}_{\mathrm{LUMO}}-\mathrm{E}_{\mathrm{HOMO}}\right)$ for $\alpha-\mathrm{B}_{12}$ and $\gamma-\mathrm{B}_{28}$ surfaces are 0.046 and $0.854 \mathrm{eV}$, respectively. The energy gap of $\gamma-\mathrm{B}_{28}$ is clearly larger than that of $\alpha-B_{12}$. The narrower LUMO-HOMO energy-gap indicates that this material is more reactive. The interaction of $\mathrm{CO}_{2}$ with $\alpha-\mathrm{B}_{12}$ (adsorption energy $47.76 \mathrm{kcal} / \mathrm{mol}$ for the type A configuration) is stronger that with $\gamma-\mathrm{B}_{28}$ (adsorption energy $29.18 \mathrm{kcal} / \mathrm{mol}$ for the type A configuration). The energy gaps of the two boron materials explains the relative strength of interactions between them and $\mathrm{CO}_{2}$. Moreover, from the Mulliken charge analysis we know that the charges of the surface atoms B1 and B2 of $\alpha-B_{12}$ which interact directly with $\mathrm{CO}_{2}$ are $-0.366 \mathrm{e}$ and $-0.321 \mathrm{e}$, while the charges of two boron atoms of $\gamma-\mathrm{B}_{28}$ which interact directly with $\mathrm{CO}_{2}$ with are $0.311 \mathrm{e}$ and $-0.311 \mathrm{e}$, respectively, which also indicate the base sites of the $\alpha-B_{12}$ surface are more basic than those of $\gamma-B_{28}$ surface. The charge analysis is also consistent with the Lewis acid-base interaction of $\mathrm{CO}_{2}$ on the $\alpha-\mathrm{B}_{12}$ surface being stronger than that of $\mathrm{CO}_{2}$ with the $\gamma-\mathrm{B}_{28}$ material.

\subsection{Coverage of $\mathrm{CO}_{2}$ on $\alpha-\mathrm{B}_{12}$ and $\gamma-\mathrm{B}_{28}$ surfaces}

In the previous calculations, adsorption of one $\mathrm{CO}_{2}$ molecule on the $2 \times 2 \alpha-B_{12}$ and $\gamma-B_{28}$ surfaces was considered. In order to investigate the capacity of these boron materials for $\mathrm{CO}_{2}$ capture, calculations with higher coverage of $\mathrm{CO}_{2}$ have been carried out.

The average adsorption energies of $\mathrm{CO}_{2}$ molecules on boron surfaces are defined as

$E_{\text {ads }}=\left(E_{\text {(boron phase- } \mathrm{nCO}}\right.$ ) $\left.-\mathrm{n} E_{\mathrm{CO}_{2}}-E_{\text {(boron phase) }}\right) / \mathrm{n}$

where $\mathrm{n}$ is the number of $\mathrm{CO}_{2}$ molecules adsorbed on the boron surfaces and $E_{(\text {boron phase-nCO }}$ ) is the total energy of the boron surface with $\mathrm{CO}_{2}$ adsorbed.

Table 4 and Figure 6 list the structural properties and the absolute value of average adsorption energies $(\mathrm{kcal} / \mathrm{mol})$ with different coverage of $\mathrm{CO}_{2}$ on $\alpha-\mathrm{B}_{12}$ and $\gamma-\mathrm{B}_{28}$ surfaces with up to four molecules of $\mathrm{CO}_{2}$. We find that the $\alpha-\mathrm{B}_{12}$ and $\gamma-\mathrm{B}_{28}$ surfaces can effectively capture up to four $\mathrm{CO}_{2}$ molecules through chemisorption with configurations which are similar to those when one $\mathrm{CO}_{2}$ is

Table 4 The absolute value of average adsorption energies in $\mathrm{kcal} / \mathrm{mol}$, average bond distances (r) in $\AA$, bond angles $(\alpha)$ in deg and charge transfer (CT) in electron for two, three and four $\mathrm{CO}_{2}$ molecules adsorption on $\alpha-\mathrm{B}_{12}$ and $\gamma-\mathrm{B}_{28}$ surfaces.

\begin{tabular}{llccc}
\hline Adsorbents & Properties & Two $\mathrm{CO}_{2}$ & Three $\mathrm{CO}_{2}$ & Four $\mathrm{CO}_{2}$ \\
\hline$\alpha-\mathrm{B}_{12}$ surface & Ads & -43.19 & -38.09 & -33.79 \\
\hline
\end{tabular}

\begin{tabular}{rlrrr}
\hline $\mathrm{r}(\mathrm{B}-\mathrm{O} 1)$ & 1.473 & 1.479 & 1.481 \\
$\mathrm{r}(\mathrm{B}-\mathrm{C})$ & 1.650 & 1.661 & 1.675 \\
$\mathrm{r}(\mathrm{C}-\mathrm{O} 1)$ & 1.430 & 1.407 & 1.388 \\
$\mathrm{r}(\mathrm{C}-\mathrm{O} 2)$ & 1.201 & 1.202 & 1.201 \\
$\mathrm{r}(\mathrm{B}-\mathrm{B})$ & 1.700 & 1.703 & 1.711 \\
& $\alpha(\mathrm{O}-\mathrm{C}-\mathrm{O})$ & 123.4 & 124.6 & 125.9 \\
$\mathrm{\gamma} \mathrm{B}_{28}$ Surface & $\mathrm{CT}$ & -0.514 & -0.444 & -0.388 \\
& $\mathrm{Ads}$ & -27.61 & -25.25 & -24.29 \\
$\mathrm{r}(\mathrm{B}-\mathrm{O} 1)$ & 1.462 & 1.470 & 1.471 \\
$\mathrm{r}(\mathrm{B}-\mathrm{C})$ & 1.642 & 1.662 & 1.666 \\
$\mathrm{r}(\mathrm{C}-\mathrm{O} 1)$ & 1.435 & 1.408 & 1.198 \\
$\mathrm{r}(\mathrm{C}-\mathrm{O} 2)$ & 1.200 & 1.200 & 1.406 \\
$\mathrm{r}(\mathrm{B}-\mathrm{B})$ & 1.740 & 1.743 & 1.744 \\
& $\alpha(\mathrm{O}-\mathrm{C}-\mathrm{O})$ & 123.1 & 124.6 & 125.1 \\
$\mathrm{CT}$ & -0.489 & -0.442 & -0.408 \\
\hline
\end{tabular}

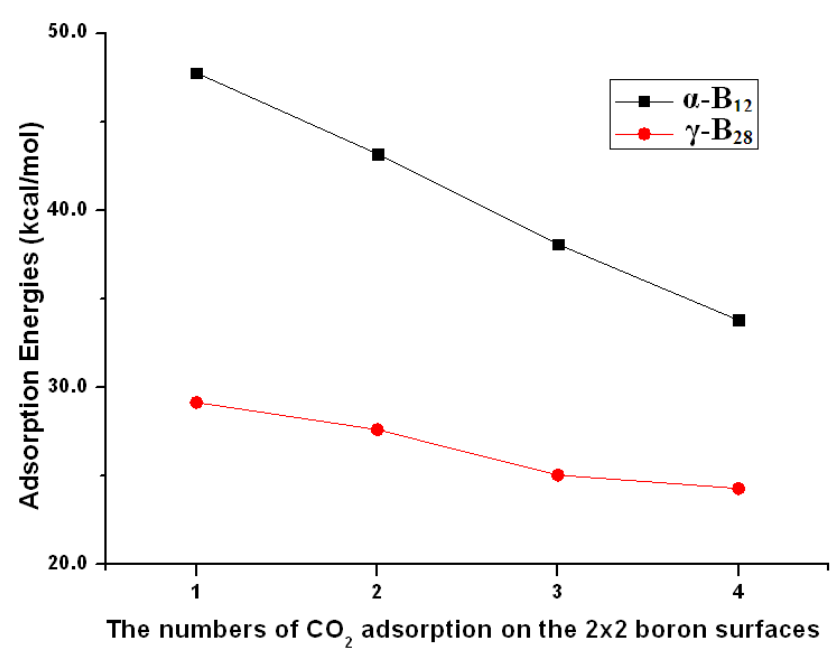

Fig. 6 The absolute value of average adsorption energies ( $\mathrm{kcal} / \mathrm{mol}$ ) with two, three and four $\mathrm{CO}_{2}$ molecules adsorption on $2 \times 2 \alpha-\mathrm{B}_{12}$ and $\gamma$ - $B_{28}$ surfaces.

adsorbed on these surfaces. However, the average adsorption energies reduce with increasing of $\mathrm{CO}_{2}$ coverage. In detail, the adsorption energies for $\mathrm{CO}_{2}$ molecules adsorbed on $2 \times 2 \alpha-\mathrm{B}_{12}$ reduce from -47.76 to $-33.79 \mathrm{kcal} / \mathrm{mol}$ as the number of $\mathrm{CO}_{2}$ molecules increases from one to four, with the energy required to remove one $\mathrm{CO}_{2}$ molecule from the system with four adsorbed being $-20.89 \mathrm{kcal} / \mathrm{mol}$. As the number of $\mathrm{CO}_{2}$ molecules adsorbed on $2 \times 2$ $\gamma-\mathrm{B}_{28}$ increases from one to four, the average adsorption energies reduce from -29.19 to $-24.29 \mathrm{kcal} / \mathrm{mol}$, with the energy required to remove one $\mathrm{CO}_{2}$ molecule from the system with four adsorbed being $-21.41 \mathrm{kcal} / \mathrm{mol}$. These results indicate that the binding of additional $\mathrm{CO}_{2}$ molecules will be weaker. This means that although the energy required to completely regenerate the clean boron would be high, boron solid which is partly covered by $\mathrm{CO}_{2}$ molecules would be a useful material for $\mathrm{CO}_{2}$ capture. Therefore pure solid boron could be used a material for permanent capture of $\mathrm{CO}_{2}$; or alternatively the solid boron functionalised with $\mathrm{CO}_{2}$ could be used as a material for capture of further $\mathrm{CO}_{2}$ and release of the additional $\mathrm{CO}_{2}$.

\section{Conclusions}


Using DFT calculations we have investigated the reaction mechanisms for $\mathrm{CO}_{2}$ capture on $\alpha-\mathrm{B}_{12}$ and $\gamma-\mathrm{B}_{28}$ surfaces. We found that these "electron deficient" boron solids perform well in capturing $\mathrm{CO}_{2}$ on the basic sites of these boron surfaces due to Lewis acid-base interactions. The absorption energy of $\mathrm{CO}_{2}$ with their strongest adsorption configurations on $\alpha-\mathrm{B}_{12}$ and $\gamma-\mathrm{B}_{28}$ boron phases are 47.76 and $29.18 \mathrm{kcal} / \mathrm{mol}$, respectively, and the barriers of these adsorption processes from their physisorbed to chemisorbed configurations are very low. Moreover, the values of the changes of Gibbs free energy for capture of free $\mathrm{CO}_{2}$ on $\alpha-\mathrm{B}_{12}$ and $\gamma-\mathrm{B}_{28}$ surfaces to form chemisorbed configurations are negative over the temperature range $200 \sim 1000 \mathrm{~K}$, which indicate the reactions are spontaneous within this temperature range. The calculations also show the binding between $\mathrm{CO}_{2}$ and the materials become weaker as the $\mathrm{CO}_{2}$ coverage increases. In addition, the modelling suggests that the solid boron materials can effectively capture $\mathrm{CO}_{2}$, and should stimulate some further experiments to verify our theoretical prediction.

\section{Acknowledgements}

Q. S. and M. W acknowledge financial support from Early Career Researcher grant of The University of Queensland. A. D. greatly appreciates financial support of the Australian Research Council QEII Fellowship. We also acknowledge generous grants of high performance computer time from both The University of Queensland and the National Computational Infrastructure (NCI).

\section{Notes and references}

1. D. W. Keith, Science 2009, 325, 1654.

2. R. S. Haszeldine, Science 2009, 325, 1647.

3. R. J. Hook, Ind. Eng. Chem. Re. 1997, 36, 1779.

4. Y. Belmabkhout and A. Sayari, Chem. Eng. Sci. 2009, 64, 3729.

5. D. E. Sands and J. L. Hoard, J. Am. Chem. Soc. 1957, 79, 5582.

6. L. V. McCarty, J. S. Kasper, F. H. Horn, B. F. Decker and A. E. Newkirk, J. Am. Chem. Soc. 1958, 80, 2592.

7. C. P. Talley, Acta Cryst. 1960, 13, 271.

8. A. R. Oganov, J. Chen, C. Gatti, Y. Ma, Y. Ma, C. W. Glass, Z. Liu, T. Yu, O. O. Kurakevych and V. L. Solozhenko, Nature 2009, 457, 863.

9. D. Li, Y. N. Xu and W. Y. Ching, Phys. Rev. B 1992, 45, 5895.

10. J. L. He, E. D. Wu, H. T. Wang, R. P. Liu and Y. J. Tian, Phys. Rev. Lett. 2005, 94, 015504.

11. G. Will and B. Kiefer, Z. Anorg. Allg. Chem. 2001, 627, 2100.

12. A. R. Oganov and V. L. Solozhenko, J. Superhard Mat. 2009, 31, 285.

13. U. Häussermann and A. S. Mikhaylushkin, Inorg. Chem. 2010, 49, 11270.

14. R. H. Wentorf, Science 1965, 147, 49.

15. Y. Wang and G. H. Robinson, Science 2011, 333, 530.

16. B. Marlid, K. Larsson and J. O. Carlsson, J. Phys. Chem. B 2001, 105, 12797.

17. M. Li, Y. Li, Z. Zhou, P. Shen and Z. Chen, Nano Lett. 2009, 9, 1944.

18. P. Wagner, C. P. Ewels, I. Suarez-Martinez, V. Guiot, S. F. J. Cox, J. S. Lord and P. R. Briddon, Phys. Rev. B 2011, 83, 024101.

19. B. Delley, J. Chem. Phys. 1990, 92, 508.

20. B. Delley, J. Chem. Phys. 2000, 113, 7756.
21. J. P. Perdew, K. Burke and M. Ernzerhof, Phys. Rev. Lett. 1996, 77, 3865.

22. S. Grimme, J. Comput. Chem. 2006, 27, 1787.

23. N. G. Szwacki, A. Sadrzadeh and B. I. Yakobson, Phys. Rev. Lett. 2007, 98, 166804.

24. D. Prasad and E. D. Jemmis, Phys. Rev. Lett. 2008, 100, 165504.

25. A. K. Singh, A. Sadrzadeh and B. I. Yakobson, Nano Lett., 2008, 8, 1314.

26. Q. Sun, Z. Li, D. J. Searles, Y. Chen, G. Q. Lu and A. J. Du, J. Am. Chem. Soc. 2013, 135, 8246.

27. Q. Sun, M. Wang, Z. Li, P. Li, W. H. Wang, X. J. Tan and A. J. Du, Fuel 2013, 109, 575.

28. Q. Sun, M. Wang, Z. Li, Y. Y. Ma and A. J. Du, Chem. Phys. Lett. 2013, 135, 59.

29. Q. Sun, M. Wang, Z. Li, A. J. Du, D. J. Searles, J. Chem. Phys. C, 2014, 118, 2170.

30. Q. Sun, Z. Li, M. Wang, A. Du and S. C. Smith, Chem. Phys. Lett. 2012, 550, 41.

31. Q. Sun, Z. Li, A. Du, J. Chen, Z. Zhu and S. C. Smith, Fuel 2012, 96, 291.

32. R. F. W. Bader, Atoms in Molecules: A Quantum Theory, Oxford University Press, Oxford, 1990.

33. T. A. Halgren and W. N. Lipscomb, Chem. Phys. Lett. 1977, 49, 225.

34. R. S. Mulliken, J. Chem. Phys. 1955, 23, 1833.

35. J. T. Muya, F. De Proft, P. Geerlings, N. Minh Tho and A. Ceulemans, J. Phys. Chem. A 2011, 115, 9069.

36. J. S. Tse, Nature 2009, 457, 800. 